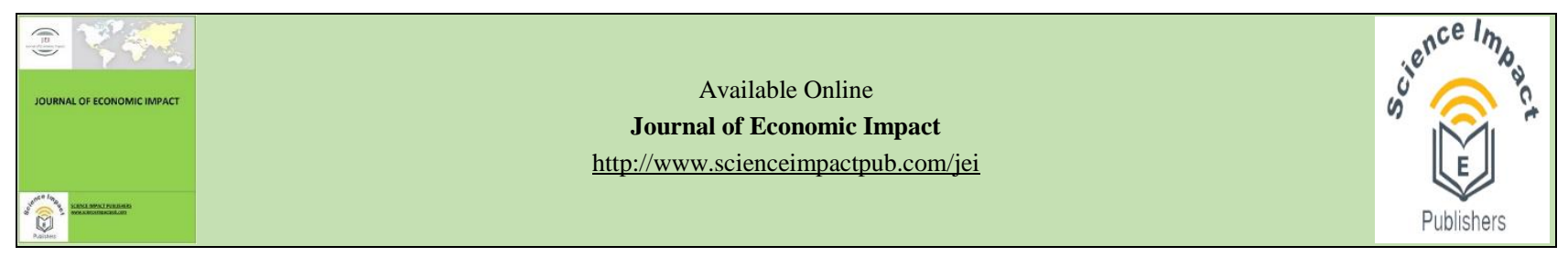

\title{
ELECTRICITY DEMAND IN PAKISTAN: A HOUSEHOLD ANALYSIS
}

\author{
Nauman Ahmed, Uzma Nisar* \\ Department of Economics, University of Lahore, Sargodha Campus, Sargodha, Pakistan.
}

\section{HIGHLIGHTS}

- At micro level analysis prices has strong and positive effect on electricity expenditures and it didn't represent traditional behavior of demand with price.

- Increase in income had positive and significant impact on demand for electricity.

- Expenditure on electricity is fairly higher during summer season.

- Number of household members have significant effect on electricity expenditure but shows very smaller influence.

- Electricity expenditure is higher for those households who are living in urban areas as compared to rural area.

$$
\text { ABSTRACT }
$$

Availability of electricity is essential in modern age because it becomes a necessity of life. The present study used some economic and non-economic determinants that affect household demand for electricity. This study used PSLM survey data for the year 2013-14. The amount of electricity consumed by household was used as dependent variable whereas electricity price, household income, appliances, heating days, region, awareness, and rooms were taken as explanatory variables. Ordinary least square technique (OLS) was used for analysis. The findings of the study showed that Economic and demographic factors are important in determining electricity expenditure. In micro level analysis prices has strong and positive effect on electricity expenditures and it didn't represent traditional behavior of demand with price. Price and income had positive impact during the period of study with demand for electricity. Expenditure on electricity is fairly higher during summer season. Positive and significant effect is estimated for stock of electricity appliances. Household members have significant effect on electricity expenditure but shows very smaller influence. The dummy variable for region indicates that electricity expenditure is higher for those households who are living in urban areas as compared to rural. Over the time period residential demand of electricity is increasing in Pakistan. As Pakistan is consumption oriented society and demand for appliances is increasing so government should take necessary measures to shift appliances on other resources other than electricity. Increasing use of the appliances increases demand for electricity therefore generation of electricity resources should be increased to meet this increasing demand.

Keywords: Electricity demand; ordinary least square; household consumption; PSLM; prices.

* Correspondence: Department of Economics, The University of Lahore, Sargodha Campus, Sargodha, Pakistan

Email: uzmanisar28@gmail.com

\section{Introduction}

In the present era, no one can deny the importance of electricity in daily life. Electricity is essential for all the sectors of economy like agricultural, industrial, commercial and residential. With the passage of time demand for electricity has been increased tremendously due to increasing trends in population growth, industrialization, urbanization and income growth and one can expect substantial increase in demand for electricity over time. The present burst of capitalization and population explosion will enhance the future need of energy specially electricity. Electricity is the biggest invention in the history of modern age. It has turned our daily routine into easy mode and in versatile manner. It has not only eliminated the darkness in our life, it is also used to run all electrical equipment to make our lives more comfortable and convenient. Since the independence Pakistan has been suffering from shortage of power due to many reasons. Firstly in 1960 era of

Ayub, dams were made which were enough for domestic and industrial usage but after decade no major hydro project has been completed. Our electricity generation installed capacity is about 23,000 MW whereas average demand for electrify is nearly 17.000 MW during summer months but still people has to face shortfall of power from $4000 \mathrm{MW}$ to $5000 \mathrm{MW}$ (GOP, 2014). In coming years it is obvious due to industrialization and increasing population will increase electricity demand by the households. Electricity is produced from different sources like Hydra, Thermal, Solar and Wind etc. Pakistan is an agricultural country with abundant of natural resources like water etc. Millions cusec water got wasted through floods during monsoon season, whereas country has to spend millions of dollar on importing oil to run its power plants. However due to high cost of electricity generation in Pakistan consumers have to bear high electricity prices. Basic point of focus is that Pakistan must realize how 
water is important for us and for our coming generation. India is continuously trying to grab more and more water by making dams. Pakistan is losing millions of tons of sweet water in Arabian Sea. So other than irrigation purposes power generation from hydra resources must be one priority of Pakistan. Pakistan is facing continuous increase in demand for electricity and also expecting in coming years. During last few years, some measures were taken to fulfill this increase demand but these steps are not sufficient to meet the electricity demand. According to National Transmission and Dispatch Company the installed capacity is $23,342 \mathrm{MW}$ in 2011 and in year 2015 it reached to $24,830 \mathrm{MW}$ from all public and private sources (GOP, 2015). According the World Bank data 93 percent households of Pakistan got electrified or connected to the national power supply system. According to these statistics residential sector of Pakistan will have lot more demand for electricity so government must ensure certain arrangements to compete with increasing demand. At present CPEC as a game changer will expected to boost our economy and it will enhance development in all sector of economy. Obviously number of consumer will increase for electricity and hence its demand. So policy makers must note the balance between consumption and generation of electricity. How much electricity is required to fulfill the needs of households is referred to as residential demand for electricity? If we are able to identify the factors that influence demand for electricity, it will be easy to estimate total requirements of energy for population.

This study is going to investigate the factors that influence household electricity demand and also finds out variation of electricity demand in different income groups of that data. Pakistan is a developing country and most of its population is poor and falls in low income group. People have to meet their expenditures under limitation of their low and fix income, so there is a continuous pressure on their financial status. A huge part of income is spent on electricity consumption as it becomes a basic commodity in residential sector. On one side Pakistan is facing the shortage of electricity and on other side paying the high prices of electricity. So for the common masses other than poverty issues, utmost and core of tension becomes electricity issues. The query that this study tries to reply is that which are the real influential ingredients of households are responsible for affecting demand for electricity. There are many factors that could affect and changes electricity demand for household. We must be vigilant and well aware about the factors that could help us to find out our estimations. Pakistan is a developing country, it has her own certain features and limitations. The present study will try to analyze those aspects that help us to estimate household demand for electricity.

Tewathia (2014) used cross section data of household of Delhi and used income, household, family size, dwelling size, stock and usage of electrical appliances, time spent by the household members and awareness level of the households as explanatory variables. As the income increases it increase purchasing capacity of the households. He used multiple regression models for his analysis. All his explanatory variables showed strong effect on monthly demand for electricity by the households of Delhi. Income elasticity level 0.28 showed that demand for income elasticity in inelastic, $0.28 \%$ increase in electricity demand will be made if there is one percent increase in income level of the households. Coefficient values showed that there were not so much changes in the explanatory variables. In Delhi demand for electricity has been increasing during hot days especially in June, July and August and demand for electricity appliances is also increasing. Households used more of $\mathrm{AC}$, refrigerators and room coolers etc. In those days and hence affect demand of electricity positively. So from many years there is in increasing trend has been seen in demand of electricity by the households.

Blazquez et al. (2012) used ordinary least square technique to identify demand for electricity by Spanish households. He made a log-log demand function to find out price elasticity's. Price, income, weather were used as predictors in his analysis. Income and price were inelastic and showed insignificant impact on demand for electricity. During summer Spanish used more electricity than during winter days and hence their demand increase. Chaudhry (2010) used cross section data of households of Lahore. Her analysis was based on short run behavior of electricity demand by the households of Lahore. She estimated the impact of income level, electrical appliances and tariff tier of electricity in Punjab province. Eighty percent households falls in first two tariff tier. It means majority are having low income and they want to spend low prices for electricity. She suggested that in third tariff tier units should be reduced up to 300 . In this way government can have more revenue due to increase number of houses in this group and households will also reduce demand for electricity. Her findings revealed that tariff policy of government is very useful tool. It positively affects income of government and negatively affects consumption of electricity. Khattak et al. (2010) used micro level data of households of district Peshawar, Pakistan. They take income, price of electricity, total number of rooms in households, education and weather conditions as major determinants of demand for electricity. Their findings showed that price was insignificant and showed nominal effect on demand for electricity whereas income, price of electricity, total number of rooms in households, education and weather conditions showed positive and some real effect on demand for electricity.

Filippini and Pachauri (2004) measured demand of electricity of urban India using micro data, in their model they tried to check the responsiveness of electricity demand to its own price, income, cross price and the geographical features likes summer, winter and monsoon. Their results proved that electricity is a necessity because seasonal effects showed that demand in income inelastic in all three seasons. Own price elasticity showed some change in demand whereas cross price effect of kerosene showed that it is a complementary to electricity because rise in kerosene oil price results in some reduction in demand for electricity in all three seasons. Burney and Akhtar (1990) used HIES data, 1984-85 of Pakistan and estimated demand for electricity of household sectors. The used electricity price, income and different fuel prices as explanatory variables. Their results showed that 
income and prices were inelastic with positive signs. Only price of firewood in rural areas showed negative sign. As they were using cross section data so their prices sign were not according to traditional demand theory. Iqbal (1983) measured income and price relationship on fuel prices (natural gas and electricity) of household in Pakistan. He observed the significance of these variables and reliability of economic theories in this analysis. His main objective was to find out about how much price of substitute fuel could be change to cut down the increased demand by households. The prices of electricity and substitute fuel had shown negative and income of households had shown positive effect on demand for electricity and natural gas. In short run impact of price and income was less than in long run analysis.

\section{Methodology}

Sample of the study was taken from Pakistan Social and Living Standard Measurement (PSLM) survey 201314. The Pakistan Bureau of Statistics (PBS) conducts this survey in Pakistan since July 2004. This survey provides comprehensive information on social and economic indicators at Provincial and District level. The data provided by PSLM survey assist the government in formulating and monitoring the development plans at national and provincial level. The log linear models used to find out the determinants of demand for electricity by household specified as follows:

$$
\begin{aligned}
& P \ln U C=\beta_{\circ}+\beta_{1} \ln M I+\beta_{2} P+\beta_{3} R+\beta_{4} A P P L+\beta_{5} H M+ \\
& \beta_{6} A W+\beta_{7} Q+\beta_{8} \operatorname{Re}+u \\
& \ln U C=\beta_{\circ}+\beta_{1} Y 1+\beta_{2} Y 2+\beta_{3} Y 3+u
\end{aligned}
$$

Where

UC: Electricity demand in a household as consumed units MI: Monthly income

P: Price of electricity

$\mathrm{R}$ : Number of total rooms in a house

APPL: Number of electrical appliances

HM: Household members

AW: Awareness

Q: Quarterly electricity consumption

Re: Region

u: Disturbance term

The description of the variables used in the current study are given in table 1 .

Table 1: Description of variables

\begin{tabular}{|c|c|c|c|c|}
\hline Units & Prices (Rs) & Frequency & Min. bill & Max. bill \\
\hline Up to 50 units & 2 & 322 & 2 & 100 \\
\hline 1 to 100 units & 5.79 & 3926 & 5.79 & 579 \\
\hline 101 to 200 units & 8.11 & 5088 & 819.11 & 1622 \\
\hline 201 to 300 units & 10.20 & 1718 & 2430.09 & 3627 \\
\hline 301 to 700 units & 16 & 441 & 4515 & 10500 \\
\hline Above 700 units & 18 & 13 & \multicolumn{2}{|c|}{12267.50 and above } \\
\hline
\end{tabular}

\begin{tabular}{ll}
\hline Variables & Description \\
\hline $\ln$ C & Natural logarithm of electricity units consumed by households \\
$\ln \mathrm{N}$ & Natural logarithm of households monthly income \\
$\mathrm{P}$ & Price of units consumed \\
$\mathrm{HM}$ & Number of household members \\
$\mathrm{NR}$ & Number of rooms a household occupy \\
$\mathrm{APPL}$ & Number of electricity appliances used by a household \\
$\mathrm{Q}$ & 1 for summer, 0 otherwise \\
$\mathrm{AW}$ & 1 for educated, 0 otherwise \\
RE & 1 for urban, 0 otherwise \\
Y1,Y2,Y3 & Income groups \\
\hline Prices paid by households for electricity usage were different electricity consumption levels and hence paying \\
given in PSLM survey data. So, electricity different prices. For the present study table 2 is \\
expenditure of households was used to calculate the proxy formulated to show the prices that are paid by the \\
for electricity prices. Different income groups have households at certain level of electricity consumption.
\end{tabular}

Table 2: Prices paid for unit's consumption

Ordinary Least Square estimation technique (OLS) is used for the empirical analysis. OLS is very useful for cross section analysis because it sums up residuals to zero and issue of heteroskedasticity could be solved conveniently. To find out the income elasticity of electricity demand $\log$ values are taken and estimated. It is one the simplest form of checking the effect of some explanatory variables on dependent variable. Main 


\section{Results and Discussion}

The original sample consists of 17,989 rural and urban households. Missing values and irreverent information were dropped from the initial sample. After cleaning and removing the missing values from the sample 11,508 households were selected for analysis. Before estimation some necessary test to check collinearity has been taken. The test results indicate that all explanatory variables are not collinear with each other. OLS estimates for both equation 1 and equation 2 are presented in table 3 and 5 respectively.

Table 3: Determinants of electricity expenditure

\begin{tabular}{|c|c|c|c|}
\hline Variables & Co-efficient & t-statistics & Prob-values \\
\hline Appliances & .007 & 5.817 & $.000 * * *$ \\
\hline Awareness & .036 & 3.698 & $.000 * *$ \\
\hline Members & .002 & 1.826 & $.068 * * *$ \\
\hline Rooms & .034 & 10.789 & $.000 * * *$ \\
\hline Price & .170 & 97.665 & $.000 * * *$ \\
\hline Region & .161 & 20.011 & $.000 * * *$ \\
\hline Income & 0.80 & 15.583 & $.000 * * *$ \\
\hline Heating days & .037 & 4.594 & $.000 * * *$ \\
\hline Constant & 2.293 & 51.853 & $.000 * * *$ \\
\hline R-Squared & \multicolumn{2}{|c|}{804} & \\
\hline Adjusted R Squared & \multicolumn{2}{|c|}{.646} & \\
\hline F-statistics & \multicolumn{2}{|c|}{$2.626 \mathrm{E} 3[.000]$} & \\
\hline SER & \multicolumn{2}{|c|}{.37901} & \\
\hline Number of observation & \multicolumn{2}{|c|}{11507} & \\
\hline
\end{tabular}

In first model all explanatory variables showed positive and significant effect on demand for electricity by households. All explanatory variables (income, appliances, region, heating days and rooms) are significant at $1 \%$ level except member. $\mathrm{R}$ squared value (0.64) sowed that all explanatory variables are explaining electricity demand so well. Second model is to look the variation of electricity expenditures in different income groups, these results are reported in table 5. In this model there is a comparison between income groups and their electricity consumption. Income groups are made from HIES 2012 report, different categories are made as shown in table 4.

Table 4: Income Groups

\begin{tabular}{ll}
\hline Groups & Income \\
\hline Poor class & Rs. 1-4000 \\
Lower class & Rs. 4001-16000 \\
Middle class & $16001-65000$ \\
Upper class & Greater than 65000 \\
\hline
\end{tabular}

Households are taken as a unit and then compared with electricity consumption in terms of units. Four income groups are made. Poor class (Rs. 1-4000) has been excluded from model and taken as reference group. By estimating linear regression between different income groups a positive and significant relationship has been seen between income groups and electricity consumption.

Lower income group spend 0.20 times more as compare to poor group. Similarly middle class and upper class spends 0.774 and 1.147 times more than as compare to poor group. It means by increase in income level of household their electricity consumption level also increased. By taking minute examination we found out that from poor group to lower class group change and increase in electricity consumption is not so much as compare to change in higher income group. There is $25.83 \%$ increase in electricity consumption in middle group from lower group whereas upper class used $67.48 \%$ more electricity than middle class which shows that when household become richer their standard of living increase and they increase their electricity consumption.

Table 5: Variation in electricity consumption in different income groups

\begin{tabular}{llll}
\hline Income groups & Coefficient & t-value & p-value \\
\hline Lower class & 0.20 & 8.068 & $.000^{* * *}$ \\
Middle class & 0.774 & 28.724 & $.000^{* * *}$ \\
\hline
\end{tabular}




\begin{tabular}{|c|c|c|c|}
\hline Upper class & 1.147 & 29.826 & $.000 * * *$ \\
\hline
\end{tabular}

According to the results of first model all explanatory variables are significant and affect the household demand for electricity positively. The member variable implies that by the addition of a new member in a household will increase electricity usage up to 0.002 percent which is not so significant. Monthly income has positive effect on the demand for electricity in residential sector. As the income of households increases they increase the stock of electrical appliance that ultimately raises their demand and expenditures on electricity. The coefficient value of monthly income indicates that one percent increase in monthly income leads to 0.037 percent increase in usage of electricity. The estimated coefficient of region dummy has shown the expected sign and significant effect on electricity demand by households. It reported that people living in cities or developed areas consume 0.161 percent more electricity than people living in rural areas. It means people living in cities or developed areas has tendency to consume more electricity because of their batter living standard. Positive results of awareness is some astonishing because it is believed that educated people save more electricity and hence consume less. In our results, awareness and unit consumed have shown positive relationship which could means that educated people acquire higher standard of living and use more electricity which results in their more expenditures on electricity. The findings indicate that more aware and more educated people use 0.036 percent more electricity than others. Dummy variable of more heating days (July, August and September) showed that during these months electricity expenditures are 0.037 percent more than other months. During summer average temperature is higher than other months of year, so household increase the use of air-conditioner and room-coolers etc. and hence demands for electricity increased during these months. Number of rooms has significant and positive relationship with consumption of electricity by households. Total number of rooms in a house was taken to analyze the impact on electricity demand. The results indicated that for each extra room demand for electricity increase up to 0.034 percent. Number of electrical appliances shows positive and significant relationship with the usage of electricity. For using an additional electronic appliance by household increases the electricity usage, although it has relatively smaller effect on electricity demand.

In a higher income household group, they use more units of electricity, they reach in new tariff block in which they had to pay more tariff for all consumed unit. Household with low electricity expenditures are paying low prices whereas households with more electricity expenditures were paying high prices. Some researchers concluded suggested that cross section data analysis is based on short run behavior of prices. Price information is uniform for the consumer and marginal electricity price need not to be taken into account (Chaudhry, 2010). Similarly Moffit (1990) pointed out that regression of electricity usage on price in an increasing block regime lead to positive slope estimates for price. So it is assumed that our analysis will show a positive relationship of price with electricity expenditures of households. In this estimation block to block or cutoff relationship of price and electricity in different from time series estimations. Most of this type of studies showed positive relationship between price and consumption of electricity by households in short period of time. It means by using more electricity households will have to pay more for it. Similar and supporting analysis was found by Chaudhry (2010), Burney and Akhtar (1990) \& Moffit, (1990).

Income elasticity of electricity demand has shown the expected positive relationship with electricity consumption. Income elasticity measures the degree of responsiveness in electricity demand resulted from any change in income. The coefficient value of monthly income (model 1) indicates that one percent increase in income level would results in 21.2 percent increase in demand for electricity by the households. The income coefficient remains low in second model comparing with first model in which price variable is not included. From the estimated models it is also found that electricity demand is income inelastic indicating that electricity is a necessary good in residential sector. Income and price are the major determinates of electricity demand. Their coefficients values showed that income and price has significant and positive relationship with electricity expenditures. Mostly people decide their consumption pattern and behavior by looking up their income level. The households fall into high income group their lifestyle becomes changes. In this way people try to transpose their lifestyle with new gadgets and living patterns. This will increase their demand for electricity and hence the usage. Moreover income has overall impact on consumption and living behavior but prices do affect in a slightly different way. Commonly consumers do not bother so much for marginal and short term change of prices; they react and respond on average or long term price behavior. Both variables showed that electricity is a basic necessity and a normal good for households.

\section{Conclusion}

The findings of the study showed that Economic and demographic factors are important in determining electricity expenditure. In micro level analysis prices has strong and positive effect on electricity expenditures and it didn't represent traditional behavior of demand with price. Price information is same and uniform for the consumer and marginal electricity price need not to be taken into account. Price and income had positive impact during the period of study with demand for electricity. Expenditure on electricity is fairly higher during summer season. Positive and significant effect is estimated for stock of electricity appliances. Household members have significant effect on electricity expenditure but shows 
very smaller influence. The dummy variable for region indicates that electricity expenditure is higher for those households who are living in urban areas as compared to rural. Over the time period residential demand of electricity is increasing in Pakistan. As Pakistan is consumption oriented society and demand for appliances is increasing so government should take necessary measures to shift appliances on other resources other than electricity. Increasing use of the appliances increases demand for electricity therefore generation of electricity resources should be increased to meet this increasing demand. Low price paying households are 9336 from 11508 and price effect more to low income households so price policy could be revised in that way that low tariff than electricity cost should be charged by low income households. Such measures should be taken that consumers must be informed that they are now going in next tariff tier in which they have to pay according to bigger and extra tariff by consuming more. District or provincial vise estimation would be more useful for further investigation and discussion.

\section{References}

Blazquez, L., Boogen, N., Filippini, M., 2012. Residential electricity demand for Spain: New empirical evidence using aggregated data, No 12-82, CEPE working paper series, CEPE Center for Energy Policy and Economics, ETH Zurich,

Burney, N.A., Akhtar, N., 1990. Fuel demand elasticities in Pakistan: An analysis of households' expenditure on fuels using micro data. The Pakistan Development Review, 29(2), 155-174.

Chaudhry, T. 2010. Estimating residential electricity demand responses in Pakistan's Punjab, The Lahore Journal of Economics, 15, 107-138.

Filippini, M., Pachauri, S., 2004. Elasticities of electricity demand in urban Indian households. Energy Policy, 32(3), 429-436.

GOP, 2014. Economic Survey of Pakistan (2013-14). Economic Advisor's Wing, Finance Division, Govt. of Pakistan, Islamabad, Pakistan

GOP, 2015. Economic Survey of Pakistan (2014-15). Economic Advisor's Wing, Finance Division, Govt. of Pakistan, Islamabad, Pakistan

Iqbal, M., 1983. Residential demand for electricity and natural gas in Pakistan. The Pakistan Development Review, 22(1), 23-36.

Khattak, N.U.R., Tariq, M., Khan, J., 2010. Determinants of household demand for electricity in District Peshawar, European Journal of Social Sciences, 14(1), 7-16.

Moffit, R., 1990. The econometrics of kinked budget constraints. The Journal of Economic Perspectives, 4 (2), $119-139$.

Tewathia, N., 2014. Determinants of household electricity consumption, International Journal of Energy Economics and Policy, 4(3), 337-48. 